\title{
Discoloration and mineralization of a textile azo dye using a hybrid $\mathrm{UV} / \mathrm{O}_{3} / \mathrm{SBR}$ process
}

\author{
Hakimeh Mahdizadeh ${ }^{1} \cdot$ Yousef Dadban Shahamat ${ }^{2} \cdot$ Susana Rodríguez-Couto $^{3,4,5}$
}

Received: 2 November 2019 / Accepted: 29 July 2021 / Published online: 9 September 2021

(c) The Author(s) 2021

\begin{abstract}
Most synthetic dyes are toxic and hardly biodegradable compounds that enter the environment mainly through the discharged of non-treated textile industry effluents. The present study investigated the removal of the textile monoazo dye Reactive Red 198 (RR-198) from aqueous solutions using the ultraviolet light and ozonation alone and in combination (i.e., $\mathrm{UV} / \mathrm{O}_{3}$ ) followed by a Sequencing Batch Reactor (SBR). The $\mathrm{pH}(5 \leq \mathrm{pH} \leq 9)$ and dye initial concentration $(50-300 \mathrm{mg} / \mathrm{L})$ parameters were optimized in the ozonation process at reaction time of 0-60 min. Then, TOC removal and dye discoloration percentage was compared with the $\mathrm{O}_{3}, \mathrm{UV}$ and $\mathrm{O}_{3} / \mathrm{UV}$ processes. In order to compare the performance of the SBR in dye discoloration of RR-198 and TOC removal, four types of effluent, including Raw dye, $\mathrm{O}_{3}$-pretreated dye, UV-treated dye and UV/ $\mathrm{O}_{3}$-pretreated dye were separately treated in the SBR system. In the ozonation process, by increasing the $\mathrm{pH}$ and reducing the initial dye concentration increased the discoloration percentage. The highest dye discoloration percentage and TOC removal obtained in the hybrid UV/O ${ }_{3} / \mathrm{SBR}$ process. Combining biological systems and Advanced Oxidation Processes is an appropriate option for the decomposition of resistant pollutants and increasing the biodegradability of these compounds and is applicable in the water and wastewater industry.
\end{abstract}

Keywords Ozonation · Ultraviolet light · Sequencing Batch Reactor · Reactive Red 198 - Textile wastewater · Azo dye

\section{Introduction}

Most synthetic dyes are recalcitrant and toxic compounds that are used in many industries such as the textile industry. More than 70,000 tons of synthetic dyes are produced annually worldwide and discarded in the industrial effluents but not all the produced dyes are discarded (Parvathi and Maruthavanan 2010). About 50\% of the used reactive

Yousef Dadban Shahamat

Dr.udadban@goums.ac.ir

1 Environmental Health Engineering Research Center, Kerman University of Medical Sciences, Kerman, Iran

2 Department of Environmental Health Engineering, Faculty of Health, Environmental Health Research Center, Golestan University of Medical Sciences, Gorgan, Iran

3 Ceit, Paseo Manuel de Lardizábal 15, 20018 San Sebastian, Spain

4 Universidad de Navarra, Paseo Manuel de Lardizábal 13, 20018 TecnunSan Sebastian, Spain

5 Basque Foundation for Science, IKERBASQUE, Maria Diaz de Haro 3, 48013 Bilbao, Spain dyes are discharged into the environment through industrial effluents (Fontana et al. 2016). Dye-containing wastewater is the most important problem in textile factories because it contains pollutants of complex structure with toxicity, carcinogenicity, mutagenicity, non-biodegradability and sustainability in the environment (Haque et al. 2015; Sivashankar et al. 2015). The discharge of untreated or improperly treated dye-containing wastewater from the textile industry into receiving waters leads to reduced sunlight penetration, impaired vision, eutrophication and interference with the ecosystem. Thus, the increase in turbidity of the aquatic bodies receiving these types of effluents provokes the decrease of the photosynthesis of aquatic plants (Dasgupta et al. 2015; Sivashankar et al. 2015). In Iran, many textile, carpet-weaving and cloth-printing industries produce a lot of wastewater containing non-biodegradable dyes that cause environmental pollution (Malakootian and Golmirzaee 2015). Reactive sulfonated dyes are highly soluble in water but they are resistant to degradation by aerobic biomass (Dasgupta et al. 2015). The monoazo textile dye Reactive Red 198 (RR-198) was selected to perform this study due to it is largely used in the textile industry, and 
it has the two groups monochloro-triazine and sulfone in its composition and is environmentally important due to its non-degradability. The processes currently used to treat textile effluents include coagulation and flocculation, chemical oxidation, biological treatment, electrochemical techniques, ion exchange, adsorption and hybrid processes including ozonation and coagulation or coagulation and ion exchange (Gupta et al. 2015; Khosravi et al. 2017; Mahmoodi et al. 2006; Moussavi and Mahmoudi 2009; Pourfadakari et al. 2016; Satapanajaru et al. 2011). These methods, however, have some disadvantages. For instance, in the adsorption process, pollution is only transferred from an aqueous phase to a solid phase. The removal of xenobiotic pollutants in biological systems takes place slowly and under particular biological conditions (Alsager et al. 2018; Farzadkia et al. 2014). As for the chemical oxidation, the high consumption of chemicals and the generation of secondary pollution by the addition of chemical compounds make this method disadvantageous. Therefore, the application of the abovementioned techniques in the industry is not practical.

One of the most effective methods for removing hazardous pollutants is the use of Advanced Oxidation Processes (AOPs) based on the production of hydroxyl free radicals with high oxidizing ability (Farzadkia et al. 2014; Rahimi et al. 2018). The main advantages of the AOPs are that they prevent the contamination by secondary products, eliminate the risk of an increased concentration of oxidizing agents and have a high speed and efficiency (Asghar et al. 2015; Malakootian et al. 2019a). The $\mathrm{UV} / \mathrm{O}_{3}$ process is an AOP whose oxidation mechanism consists of hydroxyl radical production and effective decomposition of the pollutant (Eqs. 1-4)(Beltran 2003; Malakootian et al. 2019a, 2019b).

$$
\begin{aligned}
& \mathrm{O}_{3}+\mathrm{H}_{2} \mathrm{O}+\mathrm{hv} \rightarrow \mathrm{O}_{2}+\mathrm{H}_{2} \mathrm{O}_{2} \\
& \mathrm{H}_{2} \mathrm{O}+\mathrm{hv} \rightarrow 2 \mathrm{HO} \\
& \mathrm{O}_{3}+\mathrm{H}_{2} \mathrm{O}_{2} \rightarrow \mathrm{HO}_{2}^{-\cdot}+\mathrm{HO}^{-}+\mathrm{O}_{2} \\
& \mathrm{H}_{2} \mathrm{O}_{2} \leftrightarrow \mathrm{HO}^{-2}+\mathrm{H}^{+}
\end{aligned}
$$

Ozone is a highly oxidizing agent with two oxidation mechanisms: (1) Direct oxidation and (2) Indirect oxidation by radical species $\left(\mathrm{HO}_{2}^{-\bullet}, \mathrm{HO}^{\bullet}\right)$ resulting from ozone decomposition in water (Beltran 2003; Chaturapruek 2003). Treatment by ozone can be boost by adding hydrogen peroxide, ultraviolet radiation and metal cations (Beltran 2003; Chaturapruek 2003).

Chemical treatment processes are associated with substantial costs for industries and companies, whereas activesludge biological systems, such as SBR, cannot provide the required output quality and standards for effluents containing hardly biodegradable compounds such as azo dyes. Thus, combining both systems has attracted a lot of attention from researchers in the last years (Mojiri et al. 2018). Since the author has not found a comprehensive study of the combined AOP/SBR for removal and mineralization of reactive azo dyes, in the present study the degradation of the textile reactive azo dye (RR198) using an AOP (i.e., ozonation, $\mathrm{UV}, \mathrm{UV} / \mathrm{O}_{3}$ ) followed by an SBR was studied in order to determine the most effective pretreatment. Also, this process (hybrid $\mathrm{UV} / \mathrm{O}_{3} / \mathrm{SBR}$ ) has high efficiency with simple operation.

Table 1 The molecular structure and characteristics of RR-198 [8]

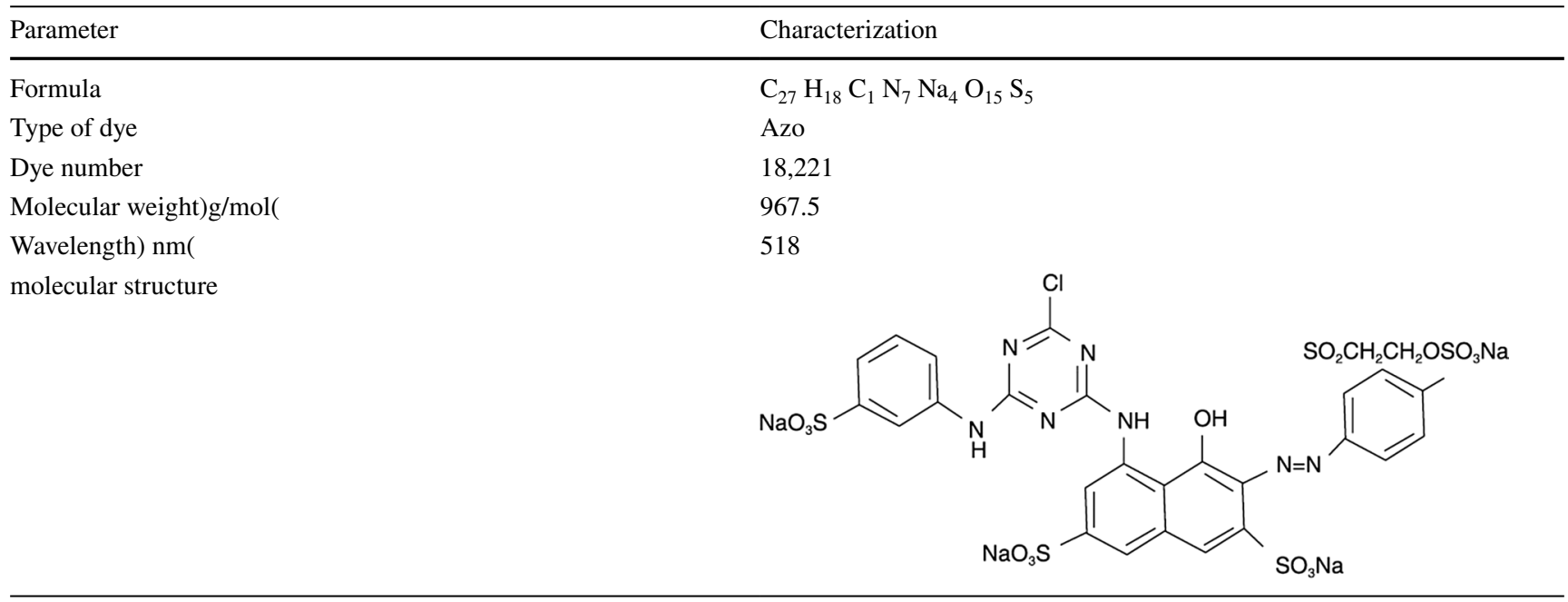




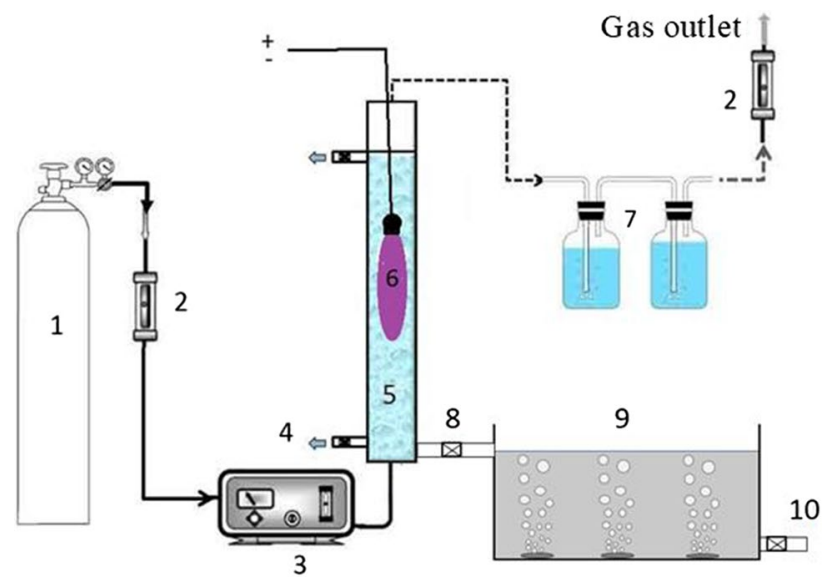

Fig. 1 (1) Oxygen cylinder; (2) Rotameter; (3) Ozone generator; (4) Sampling port; (5) Contact reactor; (6) UV lamp; (7) Gas trap; (8) Inlet valve for the SBR; (9) Sequencing batch reactor (SBR); (10) Outlet valve for the SBR

\section{Materials and methods}

\section{Chemicals}

High-purity potassium iodide, sodium hydroxide, sulfuric acid, hydrochloric acid, sodium dihydrogen phosphate, potassium dihydrogen phosphate and sodium sulfite were purchased from Merck \& Co. (Germany). The azo dye Reactive Red 198 (RR-198) with a purity of $99.8 \%$ was purchased from Alvan Paint \& Resin Production Co. (Iran). The chemical structure and the characteristics of RR-198 are shown in Table 1.

\section{Reactor design and set up}

This experimental study was carried out in a laboratory scale reactor. The schematic of the reactor is shown in Fig. 1.

The reactor was made of chemically-resistant stainless steel 315 and consisted of a cylindrical vessel $5 \mathrm{~cm}$ in inner diameter and $50 \mathrm{~cm}$ in height. The reactor operated in semibatch conditions. The ozone gas was introduced into the reactor continuously in up-flow mode at a rate of $40 \mathrm{mg} / \mathrm{L}$ min, and the dye solution was supplied into the reactor. Tubing made of ozone-resistant silicone was used to connect the different reactor parts. A polychromatic UV-C lamp (125$\mathrm{W})$ was placed inside a quartz chamber inside the contact reactor to generate UV radiation. The dye solution previously treated by $\mathrm{UV}, \mathrm{O}_{3}$ and $\mathrm{UV} / \mathrm{O}_{3}$ was then introduced into a 1-L SBR made of glass. The SBR was inoculated with condensed aerobic sludge from a municipal wastewater treatment plant representing the $33.3 \%$ working value of the reactor. The MLSS was $3500 \mathrm{mg} / \mathrm{L}$, and air was supplied from the bottom of the reactor at a flow rate of $3.5 \mathrm{~L} / \mathrm{min}$.

\section{Experimental procedure}

A $1000-\mathrm{mg} / \mathrm{L}$ stock solution of the dye RR-198 was prepared in distilled water. Different dye concentrations were prepared by appropriate dilution of the stock solution in distilled water.

The effect of the initial $\mathrm{pH}(5,6,7,8$ and 9) of the dye solution, the dye concentration $(50,100,200$ and $300 \mathrm{mg} / \mathrm{L})$ and the contact time $(0,5,10,15,30,45$ and $60 \mathrm{~min})$ on dye discoloration and TOC removal by ozonation $\left(\mathrm{O}_{3}\right)$, photolysis (UV radiation) and the hybrid system $\mathrm{UV} / \mathrm{O}_{3}$ were studied, and the optimal values for each process were determined. Then, the untreated dye and the dye pretreated by each one of the above-mentioned processes (i.e., $\mathrm{O}_{3}$, UV and $\mathrm{UV} / \mathrm{O}_{3}$ ) under optimal conditions were transferred to the SBR system. The duration of the processes in the SBR reactor included $2 \mathrm{~min}$ of filling, $4 \mathrm{~h}$ and $53 \mathrm{~min}$ of aeration and 5 min of sedimentation and discharge. The amount of organic matter was measured at different times from zero to $5 \mathrm{~h}$. The Hydraulic Retention Time (HRT) was obtained as $10 \mathrm{~h}$ given a $50 \%$ discharge of the effluent at the end of the SBR period. The temperature was maintained at $20^{\circ} \mathrm{C}$. The dye and TOC removal attained by each system were determined. The initial $\mathrm{pH}$ of the solution was adjusted by $\mathrm{H}_{2} \mathrm{SO}_{4}$ and $\mathrm{NaOH}$ solutions $(0.1 \mathrm{~N})$.

\section{Analytical determinations}

In order to determine the Total Organic Carbon (TOC), $10 \mathrm{~mL}$ of the process effluent was collected and injected with $0.1 \mathrm{~mL}$ of $1 \mathrm{~N}$ hydrochloric acid. The NPOC amount was then measured at $800{ }^{\circ} \mathrm{C}$ in the furnace by Jena-C 3100 TOC meter (Germany). Dye discoloration was determined spectrophotometrically (DR/2500, Hach USA) at the maximum visible wavelength of the dye (i.e., $518 \mathrm{~nm}$ ). Dye discoloration was expressed in terms of percentage according to the following equation:

Discoloration $(\%)=\left(A_{0}-A_{t}\right) / A_{0} \times 100$

where $A_{0}$ is the absorbance of the dye solution at time zero, and $A_{t}$ is the absorbance of the dye solution at a particular time $t$.

All experiments were performed in duplicate, and the mean and standard deviation values were calculated using the Microsoft Excel software. 

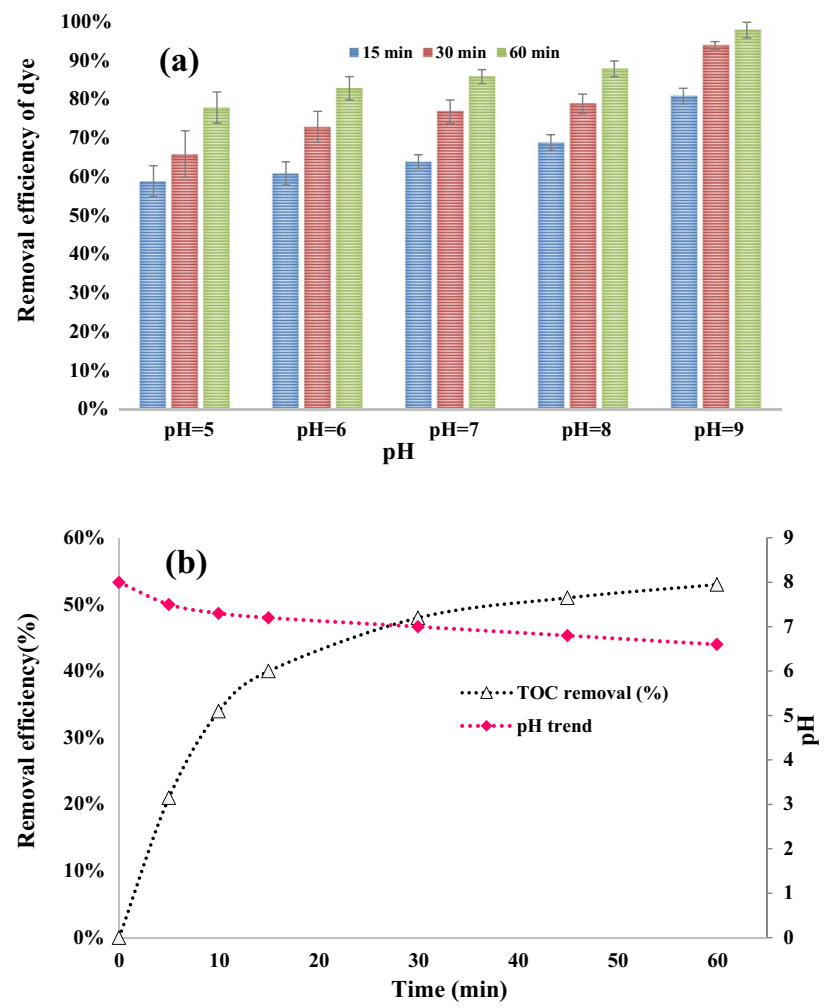

Fig. 2 The effect of the initial $\mathrm{pH}(5,6,7,8$ and 9) of the solution on dye discoloration (2a) as well as TOC removal and the changes in $\mathrm{pH}$ during the reaction time (2b) in the ozonation process ([RR-198]: $50 \mathrm{mg} / \mathrm{L}$ and ozone dose: $40 \mathrm{mg} / \mathrm{L} \mathrm{min}$ )

\section{Results and discussion}

\section{Ozonation}

\section{Effect of initial $\mathrm{pH}$ on dye and TOC removal}

In Fig. 2, the effect of the initial $\mathrm{pH}(5,6,7,8$ and 9) of the solution on RR-198 discoloration (2a), TOC removal and the changes in $\mathrm{pH}$ during the reaction time in the ozonation process $(2 b)$ is shown.

The initial $\mathrm{pH}$ of the solution is one of the most important parameters in AOPs for the degradation of organic compounds present in wastewater. By increasing the initial $\mathrm{pH}$ of the solution from 5 to 9 , the discoloration percentage increased from 59 to $81 \%$ in $15 \mathrm{~min}$ and from 66 to $94 \%$ in $30 \mathrm{~min}$. Due to the fact that the effluent $\mathrm{pH}$ of most industries is usually in the range of $6-8$, the $\mathrm{pH}$ of 8 was chosen as the optimal level. At the end of the $60 \mathrm{~min}$ of reaction time, $\mathrm{pH}$ decreased from 8 to 6.6, and dye discoloration and TOC removal reached $98 \%$ and $53 \%$, respectively.

In the ozonation process, in acidic conditions, ozone directly attacks a specific portion of organic compounds that have aromatic rings with carbon double bonds $(\mathrm{C}=\mathrm{C})$
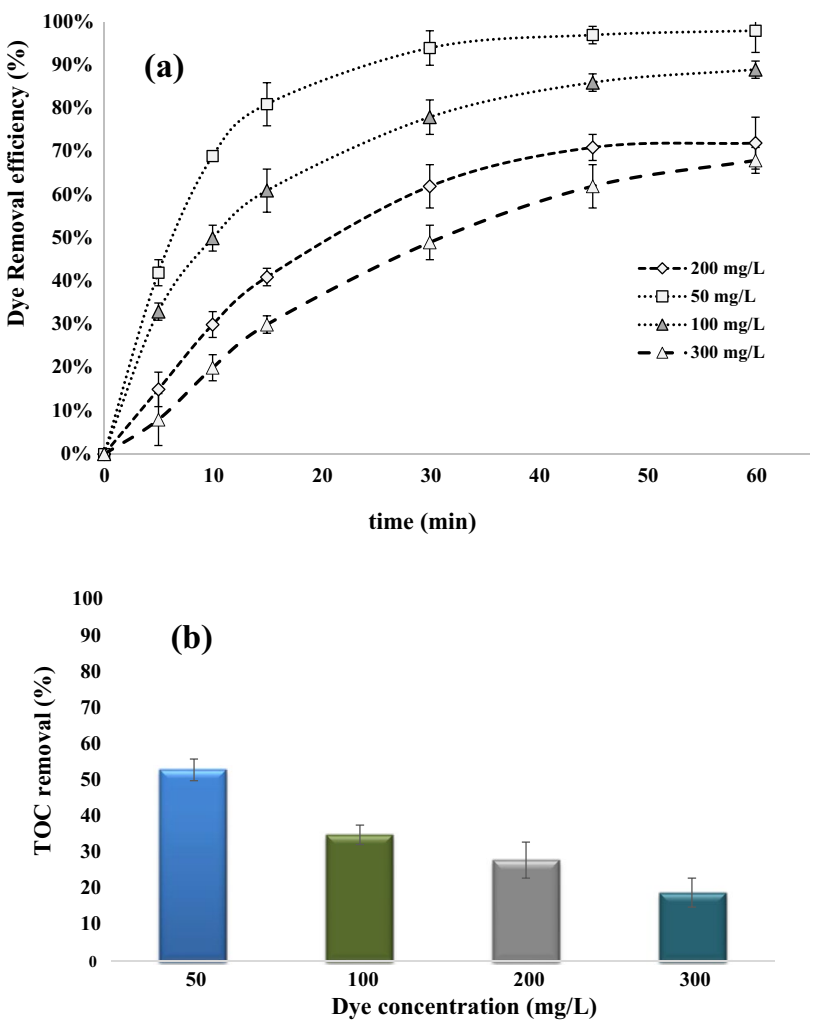

Fig. 3 Effect of the initial dye concentration on dye discoloration (2a) and TOC removal $(2 b)$ in the ozonation process at an initial $\mathrm{pH}$ of 8

and converts them to final products such as aldehydes and carboxylic acid. Also, at a low $\mathrm{pH}$, the high concentration of proton $\left(\mathrm{H}^{+}\right)$, which has a high tendency to combine with hydroxyl anions, prevents the formation of hydroxyl radicals (Andreozzi et al. 1999; Kurniawan et al. 2006).

The ozone decomposition rate increases by an increase in $\mathrm{pH}$ followed by an increase in the concentration of $\mathrm{OH}^{-}$as the initiator of ozone decomposition, thus resulting in the formation of radical species containing oxygen and secondary oxidizing agents that are very strong and more active than the ozone molecules, such as superoxide ions $\left(\mathrm{O}_{2}{ }^{-}\right)$, $\mathrm{OH}_{2}$ radicals and $\mathrm{HO}$ radicals (Eqs. 6-7) (Chaturapruek 2003; Pillai et al. 2009).

$\mathrm{O}_{3}+\mathrm{OH}^{-} \rightarrow \mathrm{O}_{2}+\mathrm{HO}_{2}^{-}$

$\mathrm{O}_{3}+\mathrm{HO}_{2}^{-} \rightarrow$ intermediate products $\left(\mathrm{O}_{3}^{-} \cdot \mathrm{O}_{2}^{-\cdot} \cdot \mathrm{OH}^{-}\right)$

These radicals have a high oxidizing power and decompose organic compounds and convert them into mineral compounds such as $\mathrm{H}_{2} \mathrm{O} \mathrm{CO}$ (Kurniawan et al. 2006).

In studies by Mousavi and Mahmoudi on discoloration in a catalytic ozonation process with manganese crystals, the results showed that by increasing the initial $\mathrm{pH}$ of the 
solution from 3 to 11 , the discoloration efficiency also increases (Moussavi and Mahmoudi 2009). Qi et al. also examined a catalytic ozonation process for removing 2, 4, 6-trichloroanisole and reported the most suitable $\mathrm{pH}$ for discoloration and mineralization in the ozonation process with magnesium oxide nanoparticles as over 8 , which constitutes alkaline conditions (Qi et al. 2009). Their results are consistent with the present findings.

\section{Effect of initial dye concentration on dye and TOC removal}

In Fig. 3, the effect of different initial dye concentrations on dye discoloration and TOC removal is presented.

In the ozonation process of a dye, a portion of the soluble ozone is used in the reaction to produce active radicals, which have a higher ability to break dye into minerals and hydroxyl intermediates; another portion of the ozone reacts directly with the molecules and their intermediate compounds (Chaturapruek 2003). Since dye is effectively removed in the ozonation process, the amount of it used in the process is an important parameter contributing to the efficiency of the process. The initial concentration of the pollutant therefore plays an important role in the efficiency
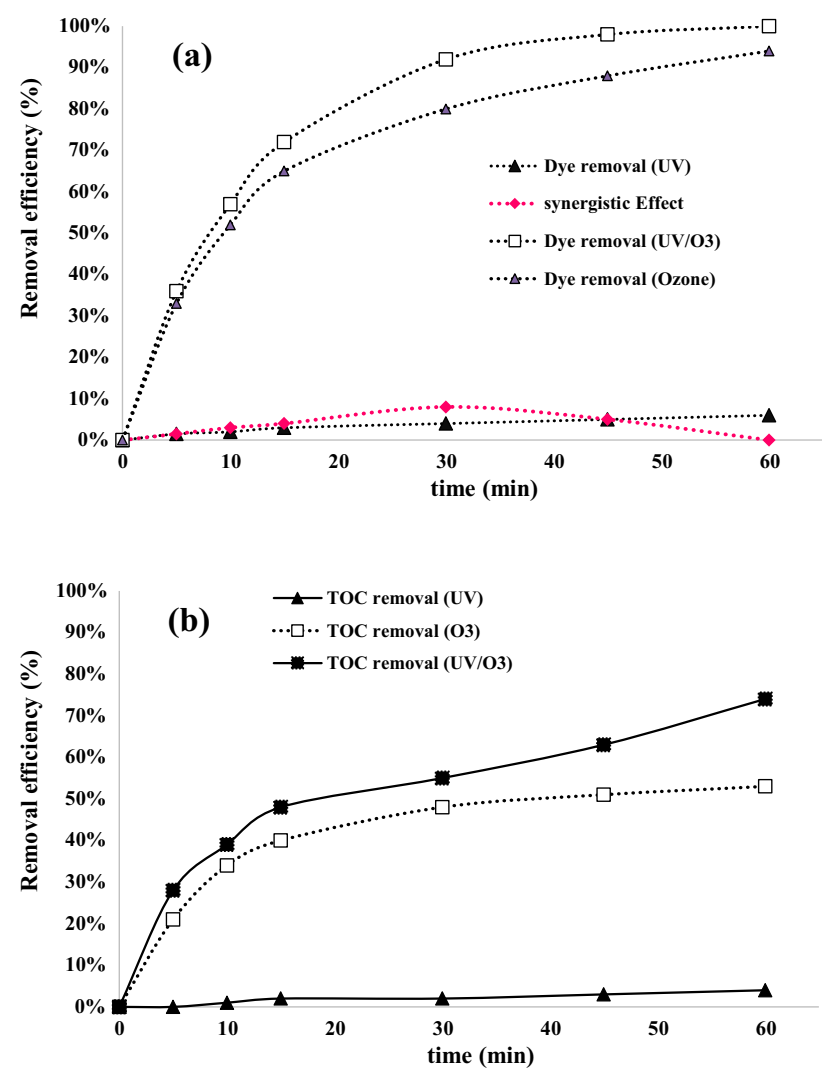

Fig. 4 Comparing the discoloration (a) and TOC (b) removal efficiency in photolysis (UV), ozonation $\left(\mathrm{O}_{3}\right)$ and hybrid $\mathrm{O}_{3} / \mathrm{UV}$ processes; ini $\mathrm{pH}=8$, [RR-198] $=50 \mathrm{mg} / \mathrm{L}, \mathrm{O}_{3}=40 \mathrm{mg} / \mathrm{L} \cdot \mathrm{min}$ of oxidation and its elimination by AOPs, such that the rate of removal is directly linked to the amount of ozone, the production of hydroxyl radicals and interaction with the amount of pollutants (Pillai et al. 2009) The results obtained by assessing the effect of dye concentration on the ozonation process showed that the highest dye discoloration (98\%) and TOC removal (53\%) were obtained for a concentration of $50 \mathrm{mg} / \mathrm{L}$ at the end of the reaction time (i.e., $60 \mathrm{~min}$ ). By increasing the dye concentration to $300 \mathrm{mg} / \mathrm{L}$, the discoloration and TOC efficiency dropped to $68 \%$ and $19 \%$ at the end of the reaction time (i.e., $60 \mathrm{~min}$ ). In AOPs, under similar conditions, only certain amounts of active radicals are produced. These process types are capable of oxidizing and eliminating certain amounts of organic compounds. It is thus obvious that, by increasing the pollutant concentration, the removal efficiency is reduced, because the number of hydroxyl radicals produced is smaller than the number of dye molecules, and these radicals are not sufficient for the degradation of all the pollutant molecules.

\section{Comparing the discoloration and TOC removal efficiency in photolysis (UV), ozonation $\left(\mathrm{O}_{3}\right)$ and hybrid $\mathrm{O}_{3} / \mathrm{UV}$ processes}

Figure $4 \mathrm{a}$ and $\mathrm{b}$ presents a comparison of the discoloration efficiency and TOC removal between photolysis (UV), ozonation $\left(\mathrm{O}_{3}\right)$ and photo-oxidation $\left(\mathrm{O}_{3} / \mathrm{UV}\right)$ processes for a constant initial dye concentration of $50 \mathrm{mg} / \mathrm{L}$. Figure $4 \mathrm{a}$ presents the synergistic effect of ozonation and UV processes using Eq. 8.

Synegistic effect $(\%)=\mathrm{UV} / \mathrm{COP}-(\mathrm{UV}+\mathrm{COP})$

In the photolysis process (UV), at the end of $60 \mathrm{~min}$ of reaction time, the dye discoloration and TOC removal were $6 \%$ and $4 \%$, respectively (Fig. 4b). The photolysis process has less decomposition power due to its low hydroxyl radical production. The dye thus showed a high resistance to UV degradation. In the ozonation process, however, the dye discoloration and TOC removal at the end of the reaction time 60 min were 94 and 53\%, respectively. The mechanism for the decomposition of organic compounds in aquatic environments by ozone takes two forms. The first mechanism is the direct oxidation of organic compounds due to the electrophilic attack of the ozone molecules, and the second one is indirect oxidation due to the attack of the hydroxyl radicals resulting from ozone decomposition. The oxidation potential of $\mathrm{OH}$ radicals is $2.33 \mathrm{~V}$, while the oxidation potential of ozone is $2.07 \mathrm{~V}$ (Eqs. 9-14) (Beltran 2003; Chaturapruek 2003; Malakootian et al. 2019a).

$\mathrm{O}_{3}+\mathrm{OH}^{-} \rightarrow \mathrm{O}_{2}+\mathrm{HO}_{2}^{-}$ 
$\mathrm{O}_{3}+\mathrm{HO}_{2} \rightarrow \mathrm{HO}_{2}+\mathrm{O}_{3}^{-}$

$\mathrm{HO}_{2} \rightarrow \mathrm{O}_{2}^{-\cdot}+\mathrm{H}^{+}$

$\mathrm{O}_{3}+\mathrm{O}_{2}^{-\cdot} \rightarrow \mathrm{O}_{3}^{-\cdot}+\mathrm{O}_{2}$

$\mathrm{O}_{3}^{-\cdot}+\mathrm{H}^{+} \rightarrow \mathrm{HO}_{3}^{-}$

$\mathrm{HO}_{3} \rightarrow \mathrm{O}_{2}+\mathrm{OH}$

In the $\mathrm{O}_{3} / \mathrm{UV}$ process, at the end of 60 min of reaction time, dye discoloration and TOC removal were 100 and $74 \%$, respectively. In the $\mathrm{O}_{3} / \mathrm{UV}$ system, the decomposition of the ozone molecules was intensified according to Eqs. 15-16, and more free radicals were produced (Malakootian et al. 2019a).

$\mathrm{O}_{3} \rightarrow \mathrm{O}_{2}+\mathrm{O}\left({ }^{3} \mathrm{P}\right)$

$\mathrm{O}\left({ }^{3} \mathrm{P}\right)+\mathrm{H}_{2} \mathrm{O} \rightarrow 2 \mathrm{OH}^{\cdot}$

The highest removal efficiency thus occurred in the photo-oxidation $\left(\mathrm{O}_{3} / \mathrm{UV}\right)$ process followed by the $\mathrm{O}_{3}$ and photolysis (UV) systems.

The results also showed that, according to Eq. 2, $\mathrm{O}_{3}$ and UV processes have a synergistic effect on each other, which is at its maximum in $30 \mathrm{~min}$ of reaction time and equals $8 \%$ Similar studies have also reported the synergistic effect of ozone and other radical producing agents (Dadban Shahamat et al. 2016). In a study by Castro et al. for the removal of azo dye from effluents, the efficiency of AOPs was compared, and the ozonation process was reported to remove a higher organic pollutant load over a shorter period of time in comparison with other AOPs, such as Fenton and UV, but the TOC removal rate associated with it was not high. A pH above 8 is required for the ozonation process to be efficient. In addition, the application of ozonation alone increases the costs of operation. Combining the ozonation process with biological aerobic systems thus led to satisfactory results and helped not only increase the degradability of the organic materials, but also reduced the costs of wastewater treatment (Castro et al. 2014).

\section{Biological treatment using an SBR system}

In order to compare the performance of the SBR in dye discoloration of RR-198 and TOC removal, four types of effluent, including (1) Raw dye, (2) $\mathrm{O}_{3}$-pretreated dye, (3) UV-treated dye and (4) $\mathrm{UV} / \mathrm{O}_{3}$-pretreated dye were separately treated in the SBR system. The initial dye and TOC concentrations were 100 and $106 \mathrm{mg} / \mathrm{L}$, respectively.
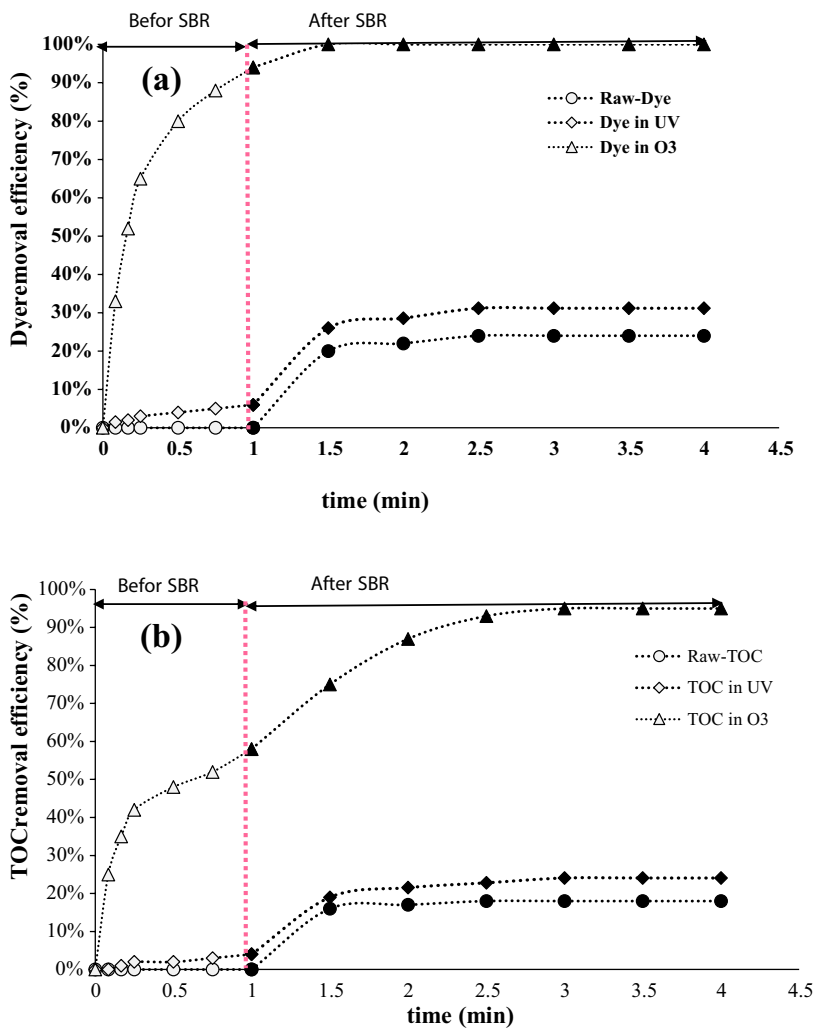

Fig. 5 The efficiency of RR-198 discoloration (a) and TOC removal (b) with ozonation pretreatment and UV-treated dye in the SBR biological process, [RR-198]: $100 \mathrm{mg} / \mathrm{L}, \mathrm{O}_{3}: 40 \mathrm{mg} / \mathrm{L} \mathrm{min}$, $\mathrm{MLSS}=3500 \mathrm{mg} / \mathrm{L}$

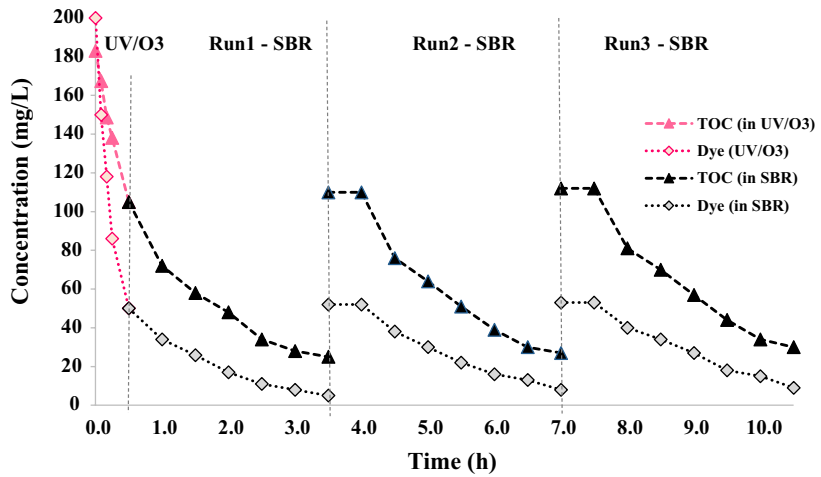

Fig. 6 The RR-198 discoloration and TOC removal rates with UV/ $\mathrm{O}_{3}$ pretreatment in the SBR biological system, [RR-198]: $200 \mathrm{mg} / \mathrm{L}$, $\mathrm{O}_{3}=40 \mathrm{mg} / \mathrm{L} \mathrm{min}, \mathrm{MLSS}=3500 \mathrm{mg} / \mathrm{L}$

\section{Effect of the pretreatment on dye discoloration and TOC removal in a SBR system}

Figure 5 presents the results of assessing the SBR biological system efficiency in RR-198 discoloration and TOC removal in raw effluent without any pretreatment, ozonated effluent and photolysis (UV-treated) effluent. 
A comparison of the discoloration and TOC removal efficiency for the effluent of the $U \mathrm{~V} / \mathrm{O}_{3}$ process by the SBR biological system

The discoloration and TOC removal efficiency of the effluent exiting the $\mathrm{UV} / \mathrm{O}_{3}$ reactor by the SBR biological system was investigated. The results are shown in Fig. 6.

As shown in Fig. 6, the dye and TOC concentrations after chemical oxidation reduced from 200 and 183 to 50 and $105 \mathrm{mg} / \mathrm{L}$ in the $\mathrm{UV} / \mathrm{O}_{3}$ process. In the biological process, the dye concentration reduced from 50 to 5,8 and $9 \mathrm{mg} / \mathrm{L}$ in the SBR reactor in three consecutive phases of treatment. Nonetheless, as an indicator of the mineralization of organic matters with an initial concentration of $105 \mathrm{mg} / \mathrm{L}$, TOC reduced to 25,27 and $30 \mathrm{mg} / \mathrm{L}$ in three consecutive phases in the SBR reactor.

The results of assessing treatment with the biological system showed that dye discoloration efficiency in the effluent of all three reactors was more than the dye mineralization efficiency using the TOC index. This phenomenon, which has been observed in most removal processes by AOPs, is caused by the formation of hardly-degradable compounds as well as some intermediate compounds such as organic acids in the process of dye oxidation that continue to produce organic matter; carboxylic acids are the most important oxidation intermediates that still have TOC, and as shown in Fig. 4b, reduced the initial $\mathrm{pH}$ of the solution from 8 to 6.6 at the end of the process (Altenor et al. 2009; Santos et al. 2005). In studies by Pachhade et al. on the removal of reactive azo dye, ozone gas was used with a flow of $2 \mathrm{~g} / \mathrm{h}$ in the presence of catalyst ions of $\mathrm{Mn}, \mathrm{Cu}, \mathrm{Fe}$ and $\mathrm{Co}$ under the ozonation process, and the results showed that discoloration was faster than organic matter removal. After 30 min of reaction time, the efficiency of dye, COD and TOC removal was $97 \%, 80 \%$ and $75 \%$, respectively (Pachhade et al. 2009). These results are consistent with the present findings.

The results showed that discoloration and TOC removal occurred more quickly in the hybrid $\mathrm{UV} / \mathrm{O}_{3} / \mathrm{SBR}$ system. The presence of the ozone gas led to the decomposition of heavy and hardly-degradable molecules into simpler and more biodegradable molecules; the TOC of the wastewater was thus reduced and organic carbon materials eventually decomposed into minerals such as $\mathrm{CO}_{2}$ and $\mathrm{H}_{2} \mathrm{O}$. Combining advanced oxidation and biological processes helped achieve the decomposition and removal of organic compounds and also ensured effluent discharge quality standards (Gommers et al. 2007).

The results obtained by Gommers et al. to remove nonbiodegradable COD using ozonation and the MBR biological system showed that the combination of oxidation and biological systems increases the BOD/COD ratio. They also concluded that the application of ozone compared to
$\mathrm{UV}$ and $\mathrm{H}_{2} \mathrm{O}_{2}$ was a more appropriate technique for wastewater biological degradation (Gommers et al. 2007). The results of a study by Pocostales et al. on the elimination of pharmaceutical products showed that the mineralization of pollutants increases by the application of ozonation due to the production of degrading radicals (Pocostales et al. 2011). The results of a study by $\mathrm{Li}$ et al. on the catalytic ozonation process of chlorinated nitroaromatic compounds (CNAC) with $\mathrm{Mn} / \mathrm{Co}$ catalyst in the SBR biological reactor showed that the treatability degree or $\mathrm{BOD} / \mathrm{COD}$ ratio increased after treatment ( $\mathrm{Li}$ et al. 2010). These results are consistent with the present findings. Nonetheless, since industrial wastewaters have a high organic load and hardlydegradable compounds, the use of ozone alone or in combination with a catalyst increases the costs of operation. This study therefore used a combination of biological systems for wastewater treatment and AOPs for the mineralization of organic compounds and discoloration. Combining ozone with biological systems is a good solution for treating wastewaters with high organic load and hardly biodegradable materials.

\section{Conclusion}

The discoloration and TOC removal efficiency in aqueous solutions were investigated by photolysis (UV radiation), $\mathrm{O}_{3}$ and $\mathrm{UV} / \mathrm{O}_{3}$ systems, and their optimal conditions were determined. The effluent of each system was introduced into the SBR for further degradation. The $\mathrm{pH}$ and dye initial concentration parameters were optimized in the ozonation process. Increasing the $\mathrm{pH}$ and decreasing the initial dye concentration will increase the dye removal efficiency. Then, the removal of TOC and dye discoloration percentage was compared with the $\mathrm{O}_{3}, \mathrm{UV}$ and $\mathrm{O}_{3} / \mathrm{UV}$ processes. In order to compare the performance of the SBR in dye discoloration of RR-198 and TOC removal, four types of effluent, including (1) Raw dye, (2) $\mathrm{O}_{3}$-pretreated dye, (3) UV-treated dye and (4) $\mathrm{UV} / \mathrm{O}_{3}$-pretreated dye were separately treated in the SBR system. In this study, the hybrid $\mathrm{UV} / \mathrm{O}_{3} / \mathrm{SBR}$ system showed the highest dye discoloration percentage and TOC removal. Biological systems are not highly efficient in decomposing resistant and hardly-degradable compounds and do not meet the water quality standards for receiving water. Combining biological systems and AOPs to treat wastewater with hardly-degradable pollutants is very efficient and is thus advised.

Acknowledgements This manuscript is part of a project titled "Investigation of $\mathrm{O}_{3} / \mathrm{UV}$ process in removal and biodegradability of azo dye (reactive red 198) with biological reactor from synthetic wastewater" with the project reference Number of 9501310280 . The authors would

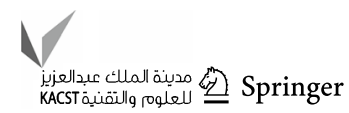


like to thank the Golestan University of Medical Sciences that provided financial and instrumental support to conduct this work.

Funding Funding was provided by Golestan University of Medical Sciences (Grant Number 9501310280).

\section{Declarations}

Conflict of interest No potential conflict of interest was reported by the authors.

Open Access This article is licensed under a Creative Commons Attribution 4.0 International License, which permits use, sharing, adaptation, distribution and reproduction in any medium or format, as long as you give appropriate credit to the original author(s) and the source, provide a link to the Creative Commons licence, and indicate if changes were made. The images or other third party material in this article are included in the article's Creative Commons licence, unless indicated otherwise in a credit line to the material. If material is not included in the article's Creative Commons licence and your intended use is not permitted by statutory regulation or exceeds the permitted use, you will need to obtain permission directly from the copyright holder. To view a copy of this licence, visit http://creativecommons.org/licenses/by/4.0/.

\section{References}

Alsager OA, Alnajrani MN, Abuelizz HA, Aldaghmani IA (2018) Removal of antibiotics from water and waste milk by ozonation: kinetics, byproducts, and antimicrobial activity. Ecotoxicol Environ safety $158: 114-122$

Altenor S, Carene B, Emmanuel E, Lambert J, Ehrhardt J-J, Gaspard S (2009) Adsorption studies of methylene blue and phenol onto vetiver roots activated carbon prepared by chemical activation. J Hazard Mater 165:1029-1039

Andreozzi R, Caprio V, Insola A, Marotta R (1999) Advanced oxidation processes (AOP) for water purification and recovery. Catalysis today 53:51-59

Asghar A, Raman AAA, Daud WMAW (2015) Advanced oxidation processes for in-situ production of hydrogen peroxide/hydroxyl radical for textile wastewater treatment: a review. J Clean Prod $87: 826-838$

Beltran FJ (2003) Ozone reaction kinetics for water and wastewater systems. CRC Press

Castro E, Avellaneda A, Marco P (2014) Combination of advanced oxidation processes and biological treatment for the removal of benzidine-derived dyes. Environ Prog Sustain Energy 33:873-885

Chaturapruek A (2003) Ozonation combined with membrane bioreactor for landfill leachate treatment. Citeseer

Dadban Shahamat Y, Sadeghi M, Shahryari A, Okhovat N, Bahrami Asl F, Baneshi MM (2016) Heterogeneous catalytic ozonation of 2, 4-dinitrophenol in aqueous solution by magnetic carbonaceous nanocomposite: catalytic activity and mechanism. Desalin Water Treat 57:20447-20456

Dasgupta J, Singh M, Sikder J, Padarthi V, Chakraborty S, Curcio S (2015) Response surface-optimized removal of Reactive Red 120 dye from its aqueous solutions using polyethyleneimine enhanced ultrafiltration. Ecotoxicol Environ safety 121:271-278

Farzadkia M, Dadban Shahamat Y, Nasseri S, Mahvi AH, Gholami M, Shahryari A (2014) Catalytic ozonation of phenolic wastewater: identification and toxicity of intermediates. J Eng 2014:1-10

Fontana KB, Chaves ES, Sanchez JD, Watanabe ER, Pietrobelli JM, Lenzi GG (2016) Textile dye removal from aqueous solutions by malt bagasse: isotherm, kinetic and thermodynamic studies. Ecotoxicol Environ safety 124:329-336

Gommers K, De Wever H, Brauns E, Peys K (2007) Recalcitrant COD degradation by an integrated system of ozonation and membrane bioreactor. Water Sci Technol 55:245-251

Gupta V, Khamparia S, Tyagi I, Jaspal D, Malviya A (2015) Decolorization of mixture of dyes: a critical review global. J Environ Sci Manage 1:71-94

Haque MM, Smith WT, Wong DK (2015) Conducting polypyrrole films as a potential tool for electrochemical treatment of azo dyes in textile wastewaters. J Hazard Mater 283:164-170

Khosravi R, Hossini H, Heidari M, Fazlzadeh M, Biglari H, Taghizadeh A, Barikbin B (2017) Electrochemical decolorization of reactive dye from synthetic wastewater by mono-polar aluminum electrodes system. Int J Electrochem Sci 12:4745-4755

Kurniawan TA, Lo W-h, Chan G (2006) Radicals-catalyzed oxidation reactions for degradation of recalcitrant compounds from landfill leachate. Chem Eng J 125:35-57

Li B-z, Xu X-y, Zhu L (2010) Catalytic ozonation-biological coupled processes for the treatment of industrial wastewater containing refractory chlorinated nitroaromatic compounds. J Zhejiang Univ Sci B 11:177-189

Mahmoodi NM, Arami M, Limaee NY (2006) Photocatalytic degradation of triazinic ring-containing azo dye (Reactive Red 198) by using immobilized $\mathrm{TiO}_{2}$ photoreactor: bench scale study. J Hazard Mater 133:113-118

Malakootian M, Golmirzaee K (2015) Evaluating the performance of advanced oxidation process by pyroxene method for removal of Reactive Red 198 in aquatic environments. J Color Sci Technol 9:199-205

Malakootian M, Gharaghani MA, Dehdarirad A, Khatami M, Ahmadian M, Heidari MR, Mahdizadeh H (2019) ZnO nanoparticles immobilized on the surface of stones to study the removal efficiency of 4-nitroaniline by the hybrid advanced oxidation process (UV/ZnO/O ${ }_{3}$ ). J Mol Struct 1176:766-776

Malakootian M, Mahdizadeh H, Dehdarirad A, Amiri Gharghani M (2019b) Photocatalytic ozonation degradation of ciprofloxacin using $\mathrm{ZnO}$ nanoparticles immobilized on the surface of stones. J Dispersion Sci Technol 40:846-854

Mojiri A, Ohashi A, Ozaki N, Kindaichi T (2018) Pollutants removal from synthetic wastewater by the combined electrochemical, adsorption and sequencing batch reactor (SBR). Ecotoxicol Environ safety 161:137-144

Moussavi G, Mahmoudi M (2009) Degradation and biodegradability improvement of the reactive red 198 azo dye using catalytic ozonation with $\mathrm{MgO}$ nanocrystals. Chem Eng J 152:1-7

Pachhade K, Sandhya S, Swaminathan K (2009) Ozonation of reactive dye, procion red MX-5B catalyzed by metal ions. J Hazard Mater 167:313-318

Parvathi C, Maruthavanan T (2010) Adsorptive removal of Megenta $\mathrm{MB}$ cold brand reactive dye by modified activated carbons derived from agricultural waste Indian. J Sci Technol 3:408-410

Pillai KC, Kwon TO, Moon IS (2009) Degradation of wastewater from terephthalic acid manufacturing process by ozonation catalyzed with $\mathrm{Fe}^{2+}, \mathrm{H}_{2} \mathrm{O}_{2}$ and UV light: direct versus indirect ozonation reactions. Appl Catalysis B: Environ 91:319-328

Pocostales P, Álvarez P, Beltrán F (2011) Catalytic ozonation promoted by alumina-based catalysts for the removal of some pharmaceutical compounds from water. Chem Eng J 168:1289-1295

Pourfadakari S, Yousefi N, Mahvi AH (2016) Removal of Reactive Red 198 from aqueous solution by combined method multi-walled carbon nanotubes and zero-valent iron: Equilibrium, kinetics, and thermodynamic. Chin J Chem Eng 24:1448-1455

Qi F, Xu B, Chen Z, Ma J, Sun D, Zhang L (2009) Influence of aluminum oxides surface properties on catalyzed ozonation of 2,4 6-trichloroanisole. Sep Purif Technol 66:405-410 
Rahimi E, Dadban Shahamat Y, Kamarehei B, Zafarzadeh A, Khani MR (2018) Rapid decolorization and mineralization of molasses by catalytic ozonation process with a nanocomposite from fermentation industry wastewater. Int J Environ Sci Technol 15(9:19411948. https://doi.org/10.1007/s13762-017-1515-8

Santos A, Yustos P, Cordero T, Gomis S, Rodríguez S, García-Ochoa F (2005) Catalytic wet oxidation of phenol on active carbon: stability, phenol conversion and mineralization. Catalysis Today 102-103:213-218. https://doi.org/10.1016/j.cattod.2005.02.006

Satapanajaru T, Chompuchan C, Suntornchot P, Pengthamkeerati P (2011) Enhancing decolorization of Reactive Black 5 and
Reactive Red 198 during nano zerovalent iron treatment. Desalination 266:218-230

Sivashankar R, Sathya A, Sivasubramanian V (2015) Synthesis of magnetic biocomposite for efficient adsorption of azo dye from aqueous solution. Ecotoxicol Environ Saf 121:149-153

Publisher's Note Springer Nature remains neutral with regard to jurisdictional claims in published maps and institutional affiliations. 